\title{
Lab Model for a Low Power Wind Turbine System
}

\author{
C. Ghiţă ${ }^{1}$, D. I. Deaconu ${ }^{1}$, A. I. Chirilă ${ }^{1}$, \\ V. Năvrăpescu ${ }^{1}$ and D. Ilina ${ }^{1}$ \\ ${ }^{1}$ Electrical Machines and Drives Department \\ Electrical Engineering Faculty, Universitatea Politehnica Bucureşti \\ Splaiul Independenței 313 (Romania) \\ E-mail: ghita.constantin@ gmail.com
}

\begin{abstract}
Paper presents a lab low power wind turbine of $2.5 \mathrm{~kW}$. The driving propeller is modeled with an assembly of variable frequency converter, three-phase induction motor and speed reducer. Thus the motor's speed can be easily driven in the range of $(300-1500) \mathrm{rpm}$ and its size is little. The speed reducer lowers the speed 5 times so that the generator will spin in the range $(60-300) \mathrm{rpm}$. This range is usual for the propellers of wind turbines. In the end the trials of the system are presented using a specific data acquisition system.
\end{abstract}

\section{Key words}

Wind turbine, Electric energy generation, Trials.

\section{Introduction}

Renewable energy resources are fully developing from both industrial and research points of view highlighting the environment's protection [1],[2]. The development of these resources is the global trend due to the diminishing of classical energy resources. The wind energy does not pollute, it is unlimited and easy to get. The main issues are linked with the conversion efficiency and optimization [3],[4], the impact over the economic development [5], numerical simulation of the devices and the conversion processes [6]-[8]. Most used generators for wind turbine systems are permanent magnet synchronous generators [9]-[11] because the excitation field does not require a DC voltage source. The literature in the field of wind energy is very rich and it is a special chapter in electrical engineering [12]-[15].

The newest solutions for wind turbine systems do not use a gear box between the propeller and the generator due to its disadvantages, such as: bigger size, difficult maintenance, noise source, lower efficiency, lower reliability, supplementary mechanical bounds [16]. As a consequence the electric generator being directly coupled with the propeller is designed for low speeds. Thus, it has numerous pole-pairs, increased mass and volume.
In this paper a lab model for a low power wind turbine system $(2.5 \mathrm{~kW})$ is presented. To test such a system it would require an aerodynamic tunnel that it is available only in specialized labs. Because of this, the propeller is modeled by a system made from three main components: variable frequency converter, induction motor and a mechanical speed reducer. The waveform of the propeller's speed can be modeled with the converter's output frequency by applying a proportional control voltage. This voltage follows the propeller's speed profile. The range is between $(0-10) \mathrm{V}$. The presented lab model simulates a system without gear box.

\section{Lab model}

The Lab model is presented in Fig. 1. The denotes are:

(RST) three-phase grid voltage: $3 \times 380 \mathrm{~V}, 50 \mathrm{~Hz}$;

(RN) single-phase voltage grid: $220 \mathrm{~V}, 50 \mathrm{~Hz}$;

1 - frequency converter: $4 \mathrm{~kW}, 3 \times 380 \mathrm{~V},(5-60) \mathrm{Hz}$;

2 - three-phase induction motor: $3.2 \mathrm{~kW}, 3 \times 380 \mathrm{~V}$,

$50 \mathrm{~Hz}, 1425 \mathrm{rpm}$;

3 - speed reducer: ratio 5.16;

4 - propeller simulator;

5 - torque sensor: maximum torque $200 \mathrm{Nm}$;

6 - permanent magnet synchronous generator: $2.8 \mathrm{~kW}$, $3 \times 380 \mathrm{~V}, 240 \mathrm{rpm}, 52 \mathrm{~Hz}$;

7 - temperature thermocouple;

8 - single-phase rectifier: $2.8 \mathrm{~kW}, 550 \mathrm{~V}$;

9 - single-phase inverter with grid filter: $2.5 \mathrm{~kW}, 220 \mathrm{~V}$, $50 \mathrm{~Hz}$;

10 - voltage resistive transducer;

11 - data acquisition system;

12 - current transducers;

13 - data processing computer;

14 - speed sensor.

The driving propeller is modeled with assembly 4 shown in Fig.1. The speed reducer 3 was necessary in order not to use an induction motor of $3 \mathrm{~kW}$ with $240 \mathrm{rpm}$. In this 
case the motor would have been heavier than the used electric motor along with the existing speed reducer.

The wind energy is great variable and the propeller's speed usually ranges in $(60-300) \mathrm{rpm}$. The synchronous generator 6 has $\mathrm{NdFeB}$ permanent magnets (large energy), low rated speed with large number of pair-poles $(2 p=26)$ and a rated frequency of $52 \mathrm{~Hz}$. Due to the large number of poles, the generator has large diameter and weight but not so heavy as it would be the high speed generator and the appropriate gear box.

The data acquisition system shown in Fig. 1 has the following parts: torque sensor 5 is slip-ring type; speed sensor 14 is an incremental encoder; temperature sensor 7 is a thermocouple; current transducer 12 has primary rated current of $25 \mathrm{~A}$; voltage sensor 10 has primary rated current of $10 \mathrm{~mA}$; data acquisition card (11) is based on a commonplace communication port, i.e.

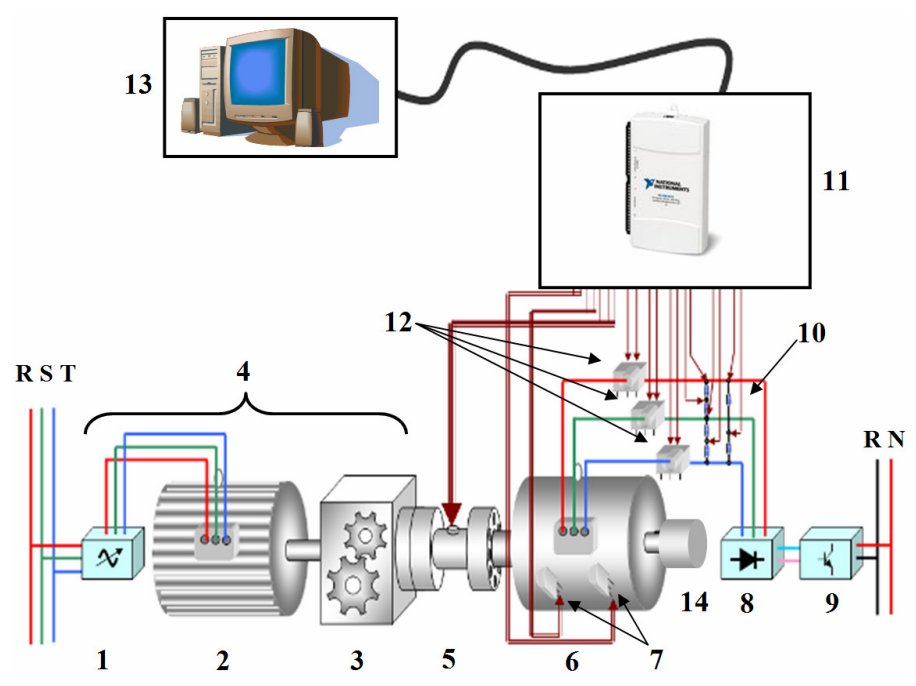

Fig. 1. System global view

USB, Windows and LabView compatible, 16 SE/8 DI analog inputs, 16 -bit resolution, $\pm 10 \mathrm{~V}$ maximum voltage range, accuracy $1.92 \mathrm{mV}, 24 \mathrm{DIO}$ digital input/output, maximum source frequency $80 \mathrm{MHz}$.

\section{Turbine speed profile modeling}

The dependency between the wind speed and turbine speed is influenced by various factors such as: turbine inertial momentum, propeller's blades type and number, controlling system of the wind turbine. Thus there is an important difference between the wind profile and turbine's speed profile. As a consequence, it is modeled the turbine's speed profile and not the wind speed profile that drives the turbine. In Fig. 2 is presented an example for a possible variation of the turbine's speed in per unit (the reference can be a convenient value).

In order to study the wind turbine system dynamics at time $t=0 \mathrm{~s}$ it is applied a speed profile $\Omega(t)$ like the one shown in Fig. 2. This is achieved by applying a control voltage $U_{c}(t)$ with a similar profile as speed. The same is for the generator's frequency $f(t)$. In Fig. 3 is presented a block diagram of the system where main quantities are shown.

In order to model the propeller speed using a voltage ranging from $(0-10) \mathrm{V}$ a convenient amplification is chosen. This amplification can be set in order to obtain for $3.2 \mathrm{~V}$ the reference speed. Thus, the system can model over the triple speed reference.

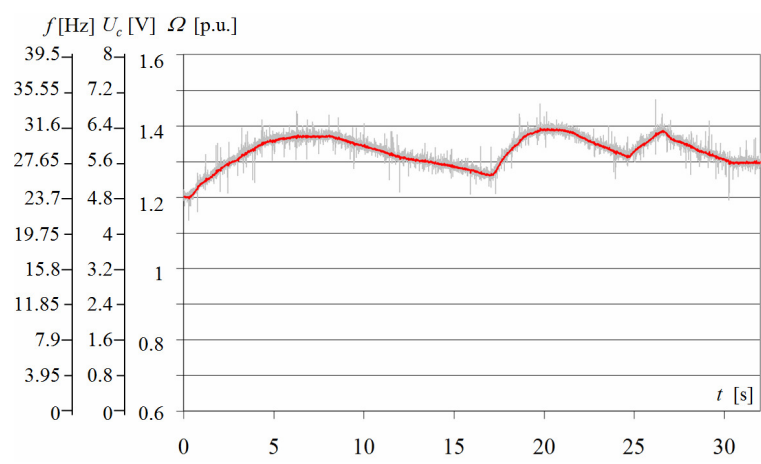

Fig. 2. Speed, control voltage and frequency profiles

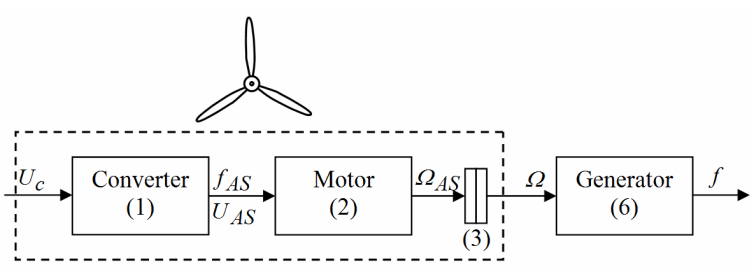

Fig. 3. Propeller model - block diagram

Control voltage $U_{c}(t)$ can be obtained from a signal generator where the user can set up any variation. This 
generator can be based on a digital to analog converter if the reference has been previously sampled.

The converter supplies the RMS voltage $U_{A S}$ that has the frequency $f_{A S}$. This frequency is in correspondence with the control voltage $U_{c}(t)$. Additionally, the frequency converter operates with $U / f=$ ct. control algorithm. Thus the maximum torque of the motor remains unchanged when frequency $f_{A S}$ changes. If this frequency is $25 \mathrm{~Hz}$ then the RMS voltage applied to the motor's terminals is half of the rated voltage, i.e. $190 \mathrm{~V}$.

\section{Model trials}

\section{B. Constant speed trials}

For the beginning the system behavior at constant speed has been analyzed. Using the measurement and data acquisition system for different speed values the following quantities have been acquired: synchronous generator's driving speed $\left(n_{G}\right)$, driving induction motor speed $\left(n_{A S}\right)$, generator's driving mechanical torque $(M)$, induction motor supplying voltage frequency $\left(f_{A S}\right)$, generator's line currents $\left(i_{A}, i_{B}, i_{C}\right)$, intermediate circuit DC voltage $\left(u_{D C}\right)$ between the rectifier and the grid connected single-phase inverter, intermediate circuit DC current $\left(i_{D C}\right)$, grid's voltage $\left(u_{R}\right)$ where the synchronous generator is connected, generator's active power $\left(P_{G}\right)$, synchronous generator's stator yoke temperature $\left(\theta_{G}\right)$.

As expected the measurements are affected by the noise. Its intensity depends on the place where the measurements are performed. In this case the measured signals have been filtered. In Fig. 4 and Fig. 5 the driving torque of the synchronous generator is presented for two different frequencies $\left(f_{A S}\right)$ of the induction motor: $25 \mathrm{~Hz}$ and $35 \mathrm{~Hz}$.

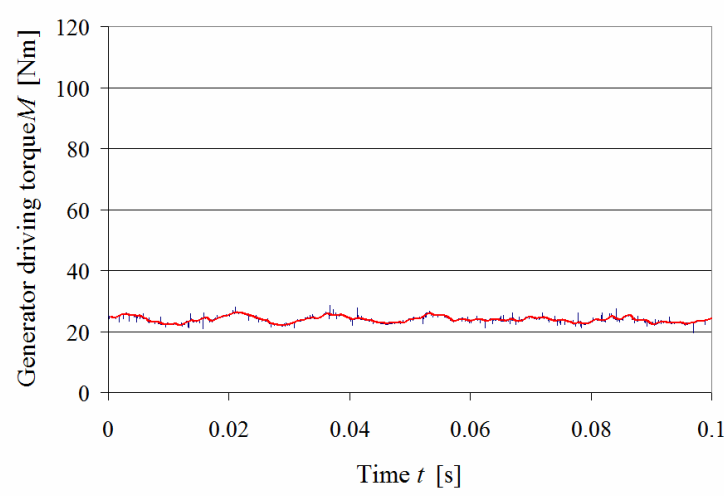

Fig. 4. The synchronous generator's driving torque for $n_{G}=139.3 \mathrm{rpm}, f_{A S}=25 \mathrm{~Hz}, u_{D C}=379 \mathrm{~V}, P_{G}=261 \mathrm{~W}$

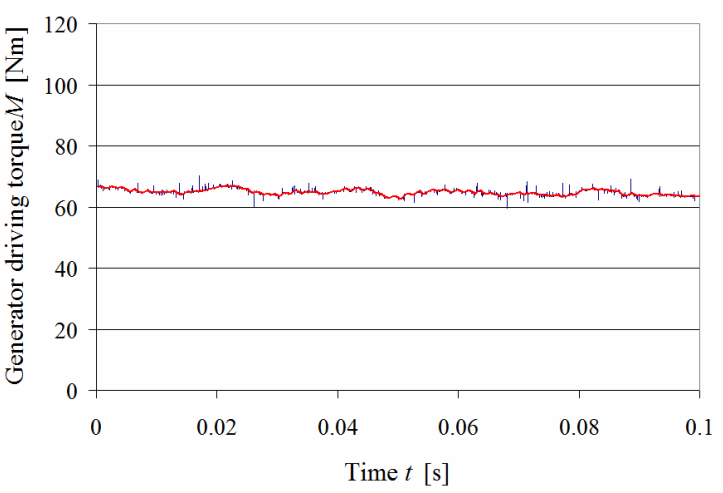

Fig. 5. The synchronous generator's driving torque for $n_{G}=189.2 \mathrm{rpm}, f_{A S}=35 \mathrm{~Hz}, u_{D C}=450 \mathrm{~V}, P_{G}=1042 \mathrm{~W}$

From Fig.4 and Fig. 5 can be observed that when the speed increases the synchronous generator driving torque is also increasing and so the active power injected into the grid. The dependency between the speed and the injected active power is shown in Fig. 6 .

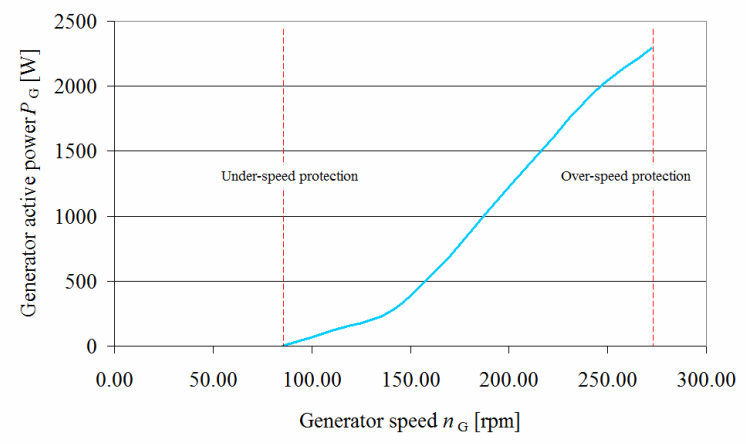

Fig. 6. Speed - generated active power curve

\section{Variable speed trials}

In case when the profile shown in Fig. 2 is required, using the data acquisition system all the quantities mentioned at the beginning of paragraph $\mathrm{A}$ can be recorded.

The control voltage $U_{c}(t)$ is applied at the converter's 1 input (Fig. 1). Its time variation is similar to the wind's profile shown in Fig. 2. The converter provides a threephase voltage system to the induction motor with variable frequency that change similar to the control voltage (Fig. 2 ). Due to the control algorithm of the converter its thus, the synchronous generator's speed is also varying as the profile presented in Fig.2 and so does the frequency of the output voltage. When the dynamics of the system is studied the following instantaneous quantities are acquired using the data acquisition system: synchronous generator's driving torque, induction motor's voltages and currents, synchronous generator's voltages and currents. In consequence, Fig. 7 depicts the generator's driving torque and Fig. 8 and Fig. 9 show the phase currents of the synchronous generator and the induction motor respectively. 


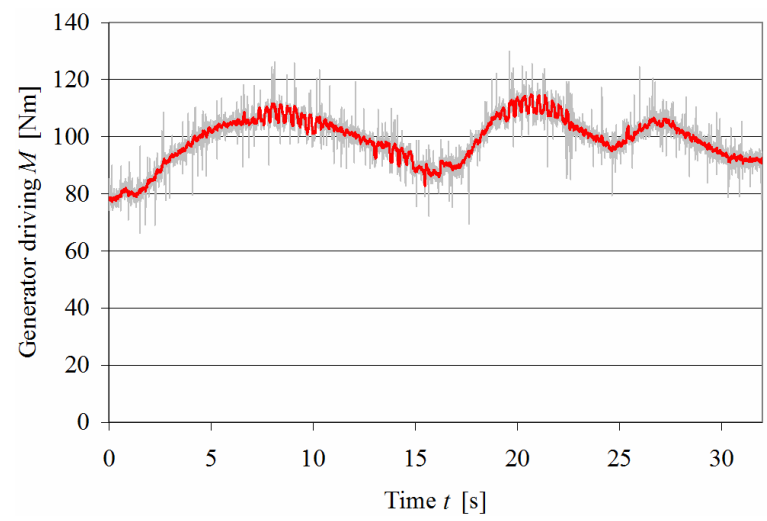

Fig. 7. Time variation of the generator's driving torque for the wind profile shown in Fig. 2.

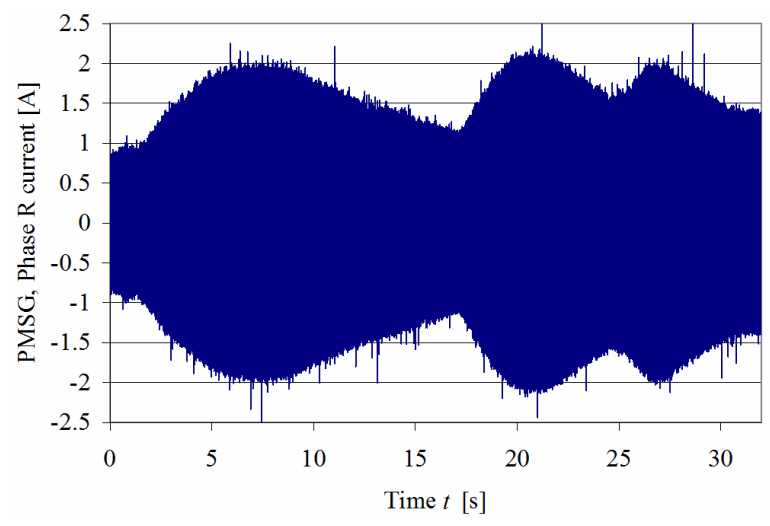

Fig. 8. Generator's phase current time variation for the wind profile shown in Fig. 2.

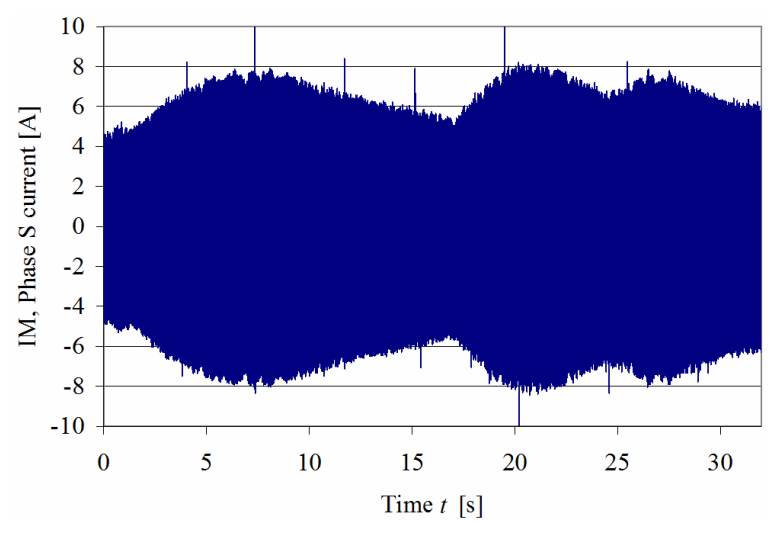

Fig. 9. Induction's motor phase current time variation for the wind profile shown in Fig. 2.

It can be observed that the torque's variation is similar to the system's speed because the converter keeps a constant ratio $U / f$. The same shapes have the envelopes of the motor's and generator's currents. The synchronous generator has a constant field due to the permanent magnets. As a result the phase back-emf of the generator has an envelope similar to the profile depicted in Fig. 2.
The phase voltage of the generator is instead constant because the voltage drops across the internal reactance are variable since the phase current is appreciable changing. In Fig. 10 is presented the output phase voltage of the generator. Its amplitude varies with less than 10 percents. This proves that the injected active power by the generator is also variable and follows the system's speed well enough.

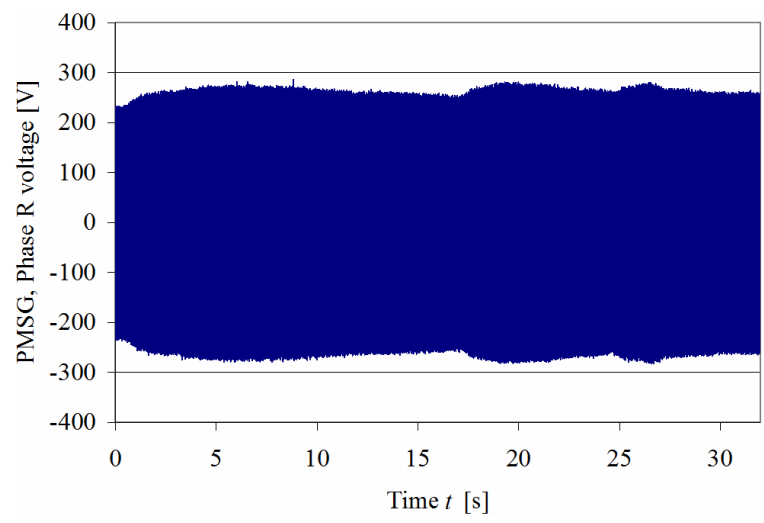

Fig. 10. Generator's phase voltage time variation for the wind profile shown in Fig. 2.

\section{Protection system}

The system is protected for both under-speed and overspeed. For $70 \mathrm{rpm}$ the wind system does not generate power. The same is for speed above $275 \mathrm{rpm}$, where the system disconnects from the grid and connects on a three-phase protection appropriate sized resistance.

The system's protections are tested when the dynamic behavior of the system is analyzed. If the generator is over-speeding there is the risk that the power injected into the grid to increase over the rated one. Such disconnection due to this over-speed is shown in Fig. 11. If the speed drops below the maximum limit then the system automatically reconnects the generator to the grid. This behavior can be observed in Fig. 12.

The system behaves quite well in abnormal operating situations by cutting off the flux power and introducing a protection resistor at generator's terminals.

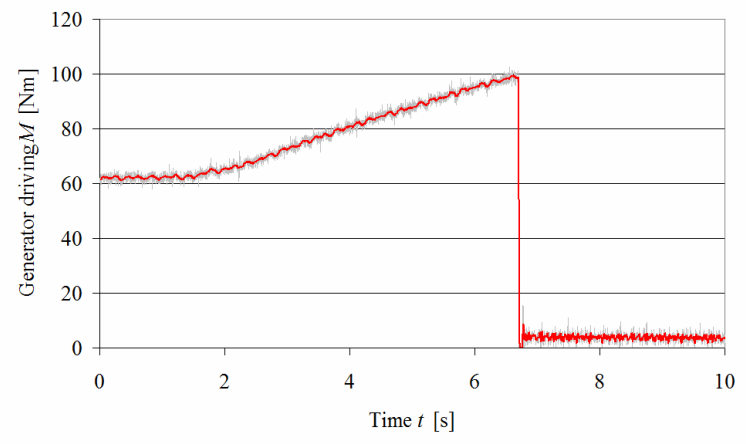

Fig. 11. System's automatic disconnection from the grid due to an over-speed event 


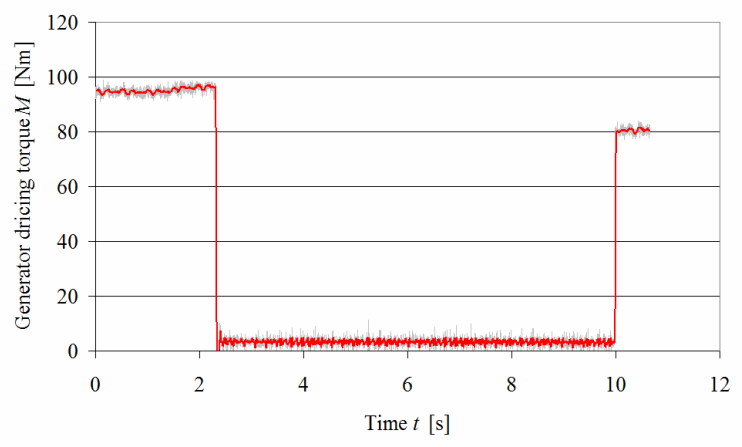

Fig. 12. System's automatic disconnection from the grid due to an over-speed event and automatic reconnection to the grid when speed is below the upper limit

\section{Conclusion}

The development of the lab model for the wind turbine system and its trials lead to the following main conclusions:

- the present trend is that the wind turbine systems not to have a gearbox;

- the generator can be induction or synchronous type, the latter one for permanent magnet variant is mostly used due to its stability on operation;

- the generator's voltage is rectified then inverted and filtered at the grid's frequency in order to be able to connect to and protect the grid from distorted generated power;

- when the generator is driven at low speed then the harmonic content of the generator's voltages and current is high;

- the protection for under-speed and over-speed is automatically performed.

- In case of substantially variable system's speed the injected active power is also variable and follows the same law as the speed does.

\section{References}

[1] O. Gol, Renewable Energy - Panacea for Climate Change, in Proc. ICREPQ'08, Santander, Spain, March 12 - 14.

[2] Intermediate Technology Development Group (ITDG)- Energy from the Wind-2007

[3] Costa, P., Martins, A., Carvalho, A., Wind energy conversion: optimization through variable speed generators and non linear fuzzy control.

[4] Vergauve, J., Martinez, A., Ribas, A., Lieven, K., Optimization of Wind Turbine using Permanent Magnet Synchronous Generator (PMSG), in Proc. ICREPQ'06, Mallorca, Spain, April 5-6.

[5] Richard Piwko, etc. The effects of Integrating Wind Power Transmission System Planning, Reliability and Operation, Albany, USA, March 4, 2005.

[6] Deaconu, I.D., Chirilă, A.I., Ghiţă, C., Năvrăpescu, V., SCIG wind turbine control system simulation models, Second International Symposium on Electrical and Electronics Engineering - ISEEE
2008, 12 - 13 September 2008, Galaţi, ROMANIA, Vol. 1, pg. $399-404$.

[7] Morten, H. etc., Control design for a pitch-regulated, variable speed wind turbine, Riso National Laboratory Rskilde, Denmark, January, 2005.

[8] DIgSILENT Application examples. Dynamic wind turbine models in power system simulation tool DIgSILENT.

[9] Tudorache, T., Melcescu, L., Popescu, M., Cistelecan, M., Finite Element Analysis of Cogging Torque in Low Permanent Magnets Wind Generators, in Proc. ICREPQ'08, Santander, Spain, March $12-14$.

[10] Predescu, M., Bejinariu, A. etc., Wind Tunnel Assessment of Small Direct Drive Wind Turbines with Permanent Magnets Synchronous Generators, in Proceedings ICREPQ'08, Santander, Spain, March 12 - 14.

[11] C. Ghiţă, A., A. I. Chirilă, I.D. Deaconu, and D.I. Ilina, Wind turbine permanent magnet synchronous generator magnetic field study, in Proc. ICREPQ'08, Santander, Spain, March 12 -14, 2008.

[12] Duran, M. J., Barrero, F. etc., Multi-phase generators viability for offshore wind farm HVDC transmission, in Proc. ICREPQ'08, Santander, Spain, March 12 - 14.

[13] Ortiz, M., Rios, J., Acosta, M., Wind Generation and Power System Interaction Analysis using Probabilistic Techniques, in Proc. ICREPQ'08, Santander, Spain, March 12 - 14.

[14] Melicio, R., Mendes, V.M.F., Catalao, J.P.S., Wind Energz Systems and Power Quality: Matrix versus Two-Level Converters, in Proc. ICREPQ'08, Santander, Spain, March 12 - 14.

[15] Vilchez, E., Stenzel, J., Wind Energy Integration into $380 \mathrm{kV}$ System - Impact on Power Quality of MV and LV Networks, in Proc. ICREPQ'08, Santander, Spain, March 12 - 14.

[16] Melissa Lane, Windmil Design Optimization through Component Costing, $\mathrm{PhD}$ thesis, Michigam State University MTH 844/490.

[17] Alessandro MARRONE, Aurel-Ionuţ CHIRILĂ, Ioan - Dragoş DEACONU, Implementation of DFIG wind turbine control system, The Sixth World Energy System Conference (WESC 2006), Torino, Italy, pp. 359-364, July 10-12, 2006. 